Check for updates

Cite this: RSC Adv., 2020, 10, 1974

Received 24th March 2020

Accepted 18th May 2020

DOI: 10.1039/dOra02702b

rsc.li/rsc-advances

\section{Emodin as a novel organic photocatalyst for selective oxidation of sulfides under mild conditions $\dagger$}

\author{
Yan Zhang, (1) t $^{\mathrm{ab}}$ Jiangli Lou, t $^{\mathrm{b}}$ Min Li, ${ }^{\mathrm{a}}$ Zhenbo Yuan (D) and Yijian Rao (iD) *a \\ Herein, we have developed naturally-occurring Emodin, which is commercially available at low-cost, as \\ a novel organic photocatalyst for the first time. Emodin was successfully employed in the selective \\ oxidation of sulfides promoted by visible-light, delivering valuable sulfoxides with high efficiency. \\ Mechanistic investigations suggested both single-electron transfer (SET) and energy transfer (EnT) \\ pathways might be involved in the oxidation reaction.
}

Visible-light-promoted reactions have attracted great interest from chemists over the past decade for the usage of sunlight as the renewable energy source. ${ }^{1}$ As a logical consequence, the development of novel photocatalysts plays an essential role in the field of photocatalysis. ${ }^{2}$ Among them, organophotocatalysts, such as Rose bengal, ${ }^{3}$ Eosin $\mathrm{Y}^{4}{ }^{4}$ 9,10-dicyanoanthracene (DCA $),{ }^{5}$ etc, were more appealing due to the avoidance of toxic, expensive and environmentally unfriendly metals (Fig. 1). ${ }^{6}$ However, the investigations of organic photocatalysts were restricted in a limited number of well-developed skeletons. Thus, it is worth further developing more varieties of organo-photocatalysts with versatile frameworks.

Meanwhile, nature generously provided plentiful natural products as high-efficient catalysts. ${ }^{7}$ Recently, we have successfully exploited cercosporin ${ }^{8}$ from plant pathogenic fungi Cercospora species as a novel photocatalyst in oxidation, ${ }^{9}$ cycloaddition $^{\mathbf{1 0}}$ and cross-coupling ${ }^{11}$ reactions. Take it into consideration that Emodin ${ }^{\mathbf{1 2}}$ has the similar quinone skeleton with hydroxy groups and photostablity (see ESI†) as cercosporin, we rationalize naturally-occurring Emodin might have potential photophysical properties ${ }^{\mathbf{1 3}}$ as a novel photoredox catalyst, which has yet not been reported to the best of our knowledge (Scheme 1a).

On the other hand, selective oxidation is a kind of fundamental reactions along with significant challenges because of the over-oxidation and the hazardous oxidizing agents employed in the reactions. ${ }^{14}$ With the growing environmental concerns, photocatalytic selective oxidation has been

${ }^{a}$ Key Laboratory of Carbohydrate Chemistry and Biotechnology, Ministry of Education, School of Biotechnology, Jiangnan University, Wuxi 214122, P. R. China. E-mail: raoyijian@jiangnan.edu.cn

${ }^{b}$ School of Pharmaceutical Science, Jiangnan University, Wuxi 214122, P. R. China $\dagger$ Electronic supplementary information (ESI) available. See DOI: 10.1039/d0ra02702b

\$ These authors contributed equally to this work. considered as an alternative method utilizing oxygen as green terminal oxidant and visible-light as renewable energy source. ${ }^{\mathbf{1 5}}$ Based on our continuous interest in developing novel photocatalysts from natural products and their applications in photoredox-catalyzed reactions, herein, we will report the first example of Emodin-catalyzed selective oxidation of sulfides with the promotion of visible-light (Scheme 1b).
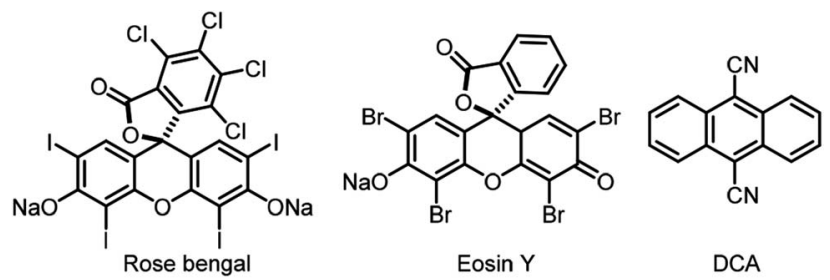

Fig. 1 Selected examples for organic photocatalysts.

a) Research design: Emodin as a novel potential photocatalyst deduced from Cercosporin

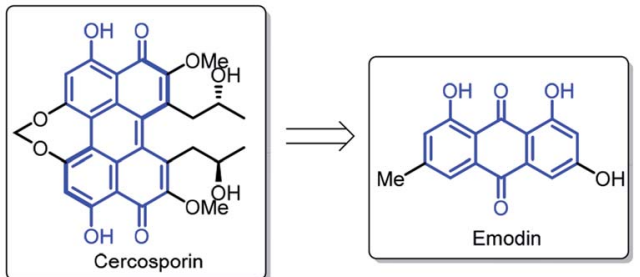

b) This work: Emodin-photocatalyzed selective oxidation of sulfides

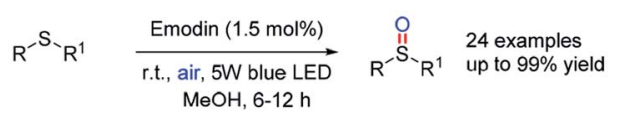

Scheme 1 Emodin-catalyzed selective oxidation of sulfides. 
Table 1 Effect of reaction parameters ${ }^{a}$

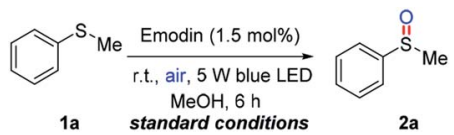

\begin{tabular}{lll}
\hline Entry & Variation from the standard conditions & Yield $^{b}(\%)$ \\
\hline 1 & None & 99 \\
2 & EtOH instead of MeOH & 82 \\
3 & DMSO instead of MeOH & 25 \\
4 & DMF instead of MeOH & 41 \\
5 & Dioxane instead of MeOH & 53 \\
6 & THF instead of MeOH & 19 \\
7 & Toluene instead of MeOH & 24 \\
8 & Emodin (2\%) instead of Emodin (1.5\%) & 99 \\
9 & Emodin (1\%) instead of Emodin (1.5\%) & 90 \\
10 & Emodin (0.5\%) instead of Emodin (1.5\%) & 76 \\
11 & 5 W CFL instead of 5 W blue LED & 71 \\
12 & 5 W green LED instead of 5 W blue LED & 29 \\
13 & 30 W blue LED instead of 5 W blue LED & 58 \\
14 & Eosin Y instead of Emodin & 93 \\
15 & Methylene blue instead of Emodin & 51 \\
16 & Methyl orange instead of Emodin & None \\
17 & Rhodamine B instead of Emodin & None
\end{tabular}

${ }^{a}$ Conducted with 1a $(0.25 \mathrm{mmol})$, Emodin $(1.5 \mathrm{~mol} \%)$ in methanol (2 $\mathrm{mL}$ ) at room temperature under air atmosphere for $6 \mathrm{~h} .{ }^{b}$ Isolated yield.

After systematic reaction condition evaluations, the selective oxidation of thioanisole was successfully achieved in 99\% yield with Emodin (1.5 mol\%) as the photocatalyst in methanol at room temperature under air atmosphere (Table 1, entry 1). Solvents screening revealed that protonic solvents $(\mathrm{MeOH}$ and

Table 2 Substrate scope of aryl alkyl sulfides ${ }^{a, b}$
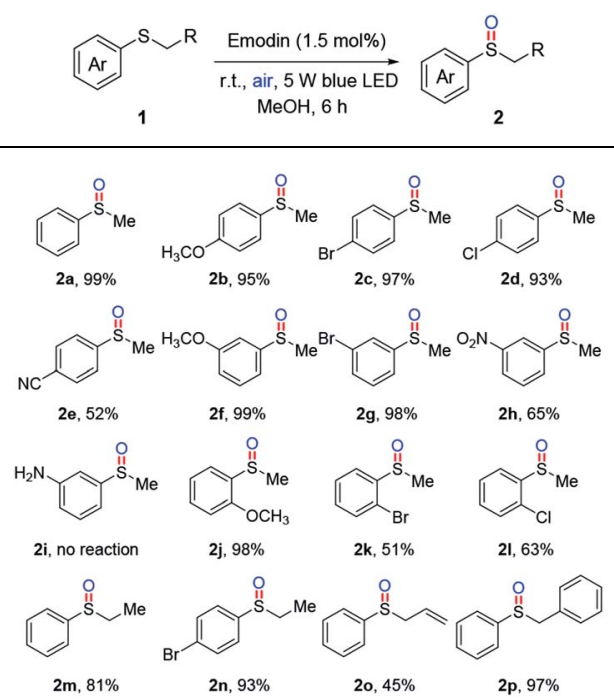

${ }^{a}$ Conducted with 1 (0.25 mmol), Emodin $(1.5 \mathrm{~mol} \%)$ in methanol (2 $\mathrm{mL}$ ) at room temperature under air atmosphere for $6-12 \mathrm{~h} .{ }^{b}$ Isolated yield.
Table 3 Substrate scope of other sulfides ${ }^{a, b}$

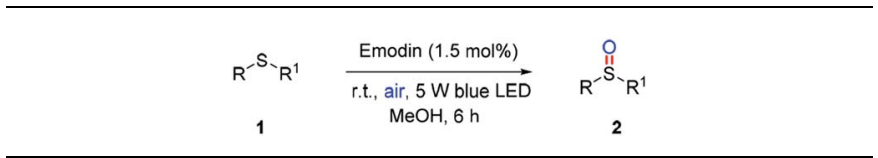
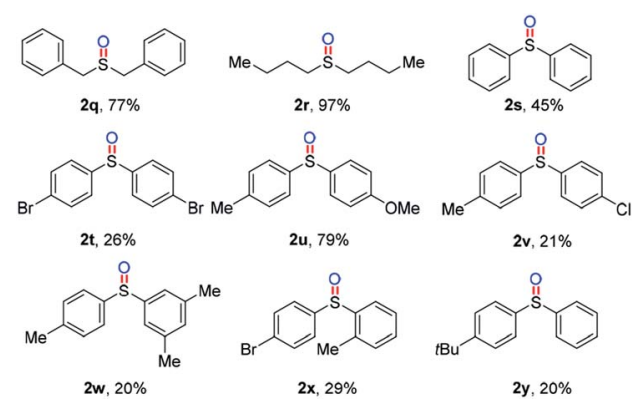

${ }^{a}$ Conducted with $1(0.25 \mathrm{mmol})$, Emodin $(1.5 \mathrm{~mol} \%)$ in methanol (2 $\mathrm{mL}$ ) at room temperature under air atmosphere for $6-12 \mathrm{~h} .{ }^{b}$ Isolated yield.

EtOH) showed better results than others like DMF, DMSO, dioxane, THF and toluene (Table 1, entries 2-7). Increasing the amount of Emodin had little influence on the reaction, while decreasing the amount to 1 and $0.5 \mathrm{~mol} \%$ would decelerate the reaction (Table 1, entries 8-10). Additionally, in this selective oxidation process, $5 \mathrm{~W}$ blue LED was proved better light source than corresponding CFL and green LED (Table 1, entries 11-12), which shows that when the maximum absorption wavelength of the photocatalyst is consistent with the emission spectrum of the light source (see ESI $\dagger$ ), the catalytic efficiency is the highest. Unexpectedly, a reduced result was obtained using $30 \mathrm{~W}$ blue LED, which probably resulted from the side-reactions induced by high energy of the light source (Table 1, entry 13). Other organic photocatatlysts were also tested, Eosin Y has the similar photocatalytic efficiency compared to Emodin (Table 1, entry 14), while the photocatalytic activities of other organic catalysts (methylene blue, methyl orange and Rhodamine B) were obviously lower than that of Emodin (Table 1, entries 15-17).

With the optimal reaction conditions, we next investigated the substrate scope of aryl alkyl sulfides, and the results were summarized in Table 2. Electron-donating group (-OMe) and halogen groups $(-\mathrm{Br},-\mathrm{Cl})$ at the para-position of the benzene ring led to the oxidation products $\mathbf{2 b - 2 d}$ in $93-99 \%$ yields; electron-withdrawing group (-CN) led to $2 \mathrm{e}$ in moderate yield. Products $\mathbf{2 f}-\mathbf{2 h}$ with meta-substitutions were produced in 65$99 \%$ yields. Unfortunately, substrate with unprotected amino group (1i) was an unsuccessful example in the reaction. When methoxy group was substituted at the ortho-position of the benzene ring, $2 \mathbf{j}$ could be delivered in $98 \%$ yield; while $\mathbf{2 k}$ and $\mathbf{2 l}$ with bromine and chlorine atoms at the ortho-position showed poor efficiency probably due to the steric hindrance. Moreover, this oxidative reaction was tolerant of ethyl $(\mathbf{2 m}, \mathbf{2 n})$, allyl (2o) and benzyl (2p) sulfides.

Subsequently, other sulfides with two alkyl groups or two aryl groups were tested (Table 3 ). Benzyl sulfoxide $\mathbf{2 q}$ and $n$-butyl 
a) Control experiments

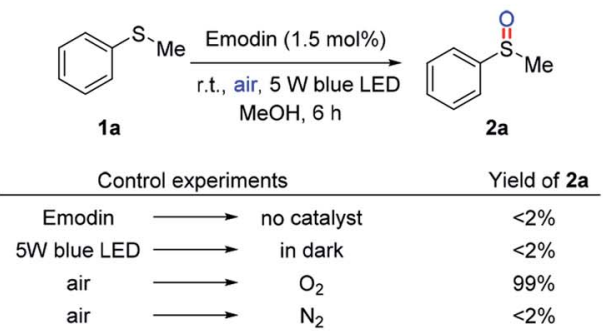

b) Radical and singlet oxygen inhibition experiments

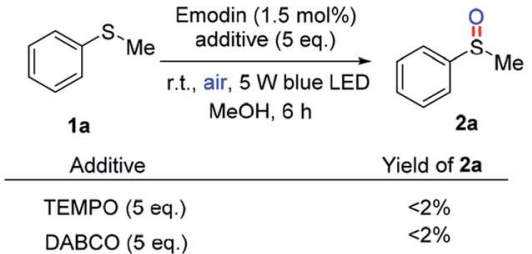

c) Proposed mechanism

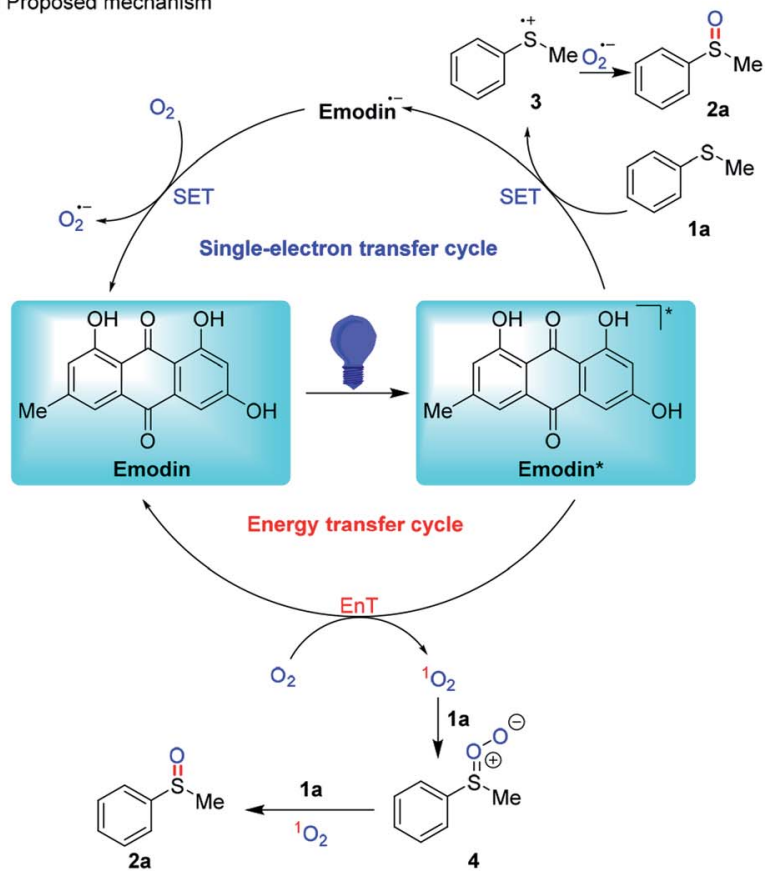

Scheme 2 Mechanistic insights.

sulfoxide $2 \mathbf{r}$ were achieved in good to excellent yields (77-97\%). What is more, symmetric (1s, 1t) and unsymmetrical (1u-1y) diphenyl sulfides were also compatible in the oxidation reactions, producing corresponding diphenyl sulfoxides $2 \mathbf{s}-2 \mathbf{y}$ in $20-79 \%$ yields.

Next, several control experiments were carried out to gain more insight into the mechanism of this novel Emodin-catalyzed oxidation reaction of sulfides. The reaction was completely inhibited without the catalyst or the light source; and the reaction was not affected when air was changed to oxygen, but failed if air was replaced by nitrogen, which revealing the roles of these factors (Scheme 2a). Furthermore, the radical and singlet oxygen inhibition experiments suggested that both $\mathrm{O}_{2}{ }^{\cdot-}$ and ${ }^{1} \mathrm{O}_{2}$ are responsible for the Emodin-catalyzed oxidation reaction of sulfides (Scheme 2b). According to the above-mentioned results and previous literature, we have proposed the reaction mechanism in Scheme 2c. First, the photocatalyst Emodin was excited with light irradiation to generate the excited species Emodin*. In the SET cycle, reductive quenching occurred to produce sulfide radical cation 3 along with the radical anion Emodin'- . Subsequently, Emodin $^{--}$was oxidized by oxygen to regenerate Emodin into the next catalytic cycle and achieve the reactive radical anion $\mathrm{O}_{2}{ }^{--}$, which further reacted with radical cation 3 to deliver methyl phenyl sulfoxide 2a. While in the EnT cycle, singlet oxygen ${ }^{1} \mathrm{O}_{2}$ was produced to oxidize 1a to the product 2a via the intermediate 4, and photocatalyst Emodin was regenerated simultaneously.

\section{Conclusions}

The natural product Emodin has been developed as a novel organic photocatalyst for the first time. Emodin-photocatalyzed selective oxidation reaction of sulfides with the promotion of visible-light proceeded in high efficiency and exhibited good functional group tolerance. Two possible mechanism including SET and Ent cycles were proposed according to the mechanistic investigations. Further investigations on Emodin-catalyzed photoredox reactions are currently underway in our laboratory.

\section{Conflicts of interest}

There are no conflicts to declare.

\section{Notes and references}

1 For selected reviews, see: (a) D. Ravelli, S. Protti and M. Fagnoni, Chem. Rev., 2016, 116, 9850-9913; (b) M. N. Hopkinson, B. Sahoo, J.-L. Li and F. Glorius, Chem.Eur. J., 2014, 20, 3874-3886; (c) D. P. Hari and B. König, Angew. Chem., Int. Ed., 2013, 52, 4734-4743; (d) C. K. Prier, D. A. Rankic and D. W. C. MacMillan, Chem. Rev., 2013, 113, 5322-5363; (e) J. Xuan and W.-J. Xiao, Angew. Chem., Int. Ed., 2012, 51, 6828-6838; (f) J. M. R. Narayanam and C. R. J. Stephenson, Chem. Soc. Rev., 2011, 40, 102-113; $(g)$ T. P. Yoon, M. A. Ischay and J. Du, Nat. Chem., 2010, 2, 527-532.

2 For selected reviews, see: (a) F. Glaser and O. S. Wenger, Coord. Chem. Rev., 2020, 405, 213129; (b) B. M. Hockin, C. Li, N. Robertson and E. Zysman-Colman, Catal. Sci. Technol., 2019, 9, 889-915; (c) D. M. Arias-Rotondo and J. K. McCusker, Chem. Soc. Rev., 2016, 45, 5803-5820; (d) D. Sudha and P. Sivakumar, Chem. Eng. Process., 2015, 97, 112-133; (e) P. Liao and E. A. Carter, Chem. Soc. Rev., 2013, 42, 2401-2422.

3 For selected review, see: (a) S. Sharma and A. Sharma, Org. Biomol. Chem., 2019, 17, 4384-4405. For selected examples, see: $(b)$ M. Singsardar, S. Mondal, S. Laru and A. Hajra, Org. Lett., 2019, 21, 5606-5610; (c) P. Li and G.-W. Wang, Org. Biomol. Chem., 2019, 17, 5578-5585; (d) J.-R. Xin, 
Y.-H. He and Z. Guan, Org. Chem. Front., 2018, 5, 1684-1688; (e) Y. Pan, C. W. Kee, L. Chen and C.-H. Tan, Green Chem., 2011, 13, 2682-2685.

4 For selected examples, see: $(a) \mathrm{K} . \mathrm{Wu}, \mathrm{L}$. Wang, S. ColónRodríguez, G.-U. Flechsig and T. Wang, Angew. Chem., Int. Ed., 2019, 58, 1774-1778; (b) G. Zhao and T. Wang, Angew. Chem., Int. Ed., 2018, 57, 6120-6124; (c) H. Wang, Y. Li, Z. Tang, S. Wang, H. Zhang, H. Cong and A. Lei, Acs Catal, 2018, 8, 10599-10605; (d) A. K. Yadav and L. D. S. Yadav, Green Chem., 2016, 18, 4240-4244; (e) M. Majek and A. J. von Wangelin, Angew. Chem., Int. Ed., 2015, 54, 22702274 .

5 For selected examples, see: (a) H.-T. Qin, X. Xu and F. Liu, Chemcatchem, 2017, 9, 1409-1412; (b) C. Yang, J.-D. Yang, Y.-H. Li, X. Li and J.-P. Cheng, J. Org. Chem., 2016, 81, 12357-12363; (c) G. Pandey and R. Laha, Angew. Chem., Int. Ed., 2015, 54, 14875-14879.

6 For selected reviews on organo-photocatalysts, see: (a) M. Z. Rahman, M. G. Kibria and C. B. Mullins, Chem. Soc. Rev., 2020, DOI: 10.1039/c9cs00313d; (b) Y. Zhang, W. Schilling and S. Das, Chemsuschem, 2019, 12, 28982910; (c) C. Li, Y. Xu, W. Tu, G. Chen and R. Xu, Green Chem., 2017, 19, 882-899; (d) N. A. Romero and D. A. Nicewicz, Chem. Rev., 2016, 116, 10075-10166; (e) S. Fukuzumi and K. Ohkubo, Org. Biomol. Chem., 2014, 12, 6059-6071.

7 For selected examples, see: $(a)$ S. B. Kasar and S. R. Thopate, Curr. Org. Synth., 2018, 15, 110-115; (b) W. Li, S. Fedosov, T. Tan, X. Xu and Z. Guo, Appl. Biochem. Biotechnol., 2014, 173, 278-290; (c) H.-F. Jiang, J.-W. Ye, C.-R. Qi and L.-B. Huang, Tetrahedron Lett., 2010, 51, 928-932.

8 For selected reviews on Emodin, see: (a) Y. Tu, Z. Wu, B. Tan, A. Yang and Z. Fang, Oncol. Rep., 2019, 42, 1259-1271; (b) L. Li, X. Song, Z. Yin, R. Jia, Z. Li, X. Zhou, Y. Zou, L. Li, L. Yin, G. Yue, G. Ye, C. Lv, W. Shi and Y. Fu, Microbiol. Res., 2016, 186, 139-145; (c) X. Dong, J. Fu, X. Yin, S. Cao,
X. Li, L. Lin, Huyiligeqi and J. Ni, Phytother. Res., 2016, 30, 1207-1218; (d) W.-T. Wei, S.-Z. Lin, D.-L. Liu and Z.-H. Wang, Oncol. Rep., 2013, 30, 2555-2562; (e) I. Izhaki, New Phytol., 2002, 155, 205-217.

9 (a) S. Kuyama and T. Tamura, J. Am. Chem. Soc., 1957, 79, 5725-5726; (b) S. Kuyama and T. Tamura, J. Am. Chem. Soc., 1957, 79, 5726-5729; (c) M. E. Daub and M. Ehrenshaft, Annu. Rev. Phytopathol., 2000, 38, 461-490; (d) M. E. Daub, Phytopathology, 1987, 77, 1515-1520.

10 J. Li, W. Bao, Z. Tang, B. Guo, S. Zhang, H. Liu, S. Huang, Y. Zhang and Y. Rao, Green Chem., 2019, 21, 6073-6081.

11 (a) J. Li, W. Bao, Y. Zhang and Y. Rao, Org. Biomol. Chem., 2019, 17, 8958-8962; (b) Y. Zhang, Y. Cao, L. Lu, S. Zhang, W. Bao, S. Huang and Y. Rao, J. Org. Chem., 2019, 84, 7711-7721.

12 (a) Z. Tang, J. Li, F. Lin, W. Bao, S. Zhang, B. Guo, S. Huang, Y. Zhang and Y. Rao, J. Catal., 2019, 380, 1-8; (b) S. Zhang, Z. Tang, W. Bao, J. Li, B. Guo, S. Huang, Y. Zhang and Y. Rao, Org. Biomol. Chem., 2019, 17, 4364-4369.

13 (a) L. Wang, Z. Zhang and B. Ye, Electrochim. Acta, 2006, 51, 5961-5965; (b) D. Li and B. Jin, J. Electrochem., 2017, 23, 347355.

14 For selected reviews on selective oxidation reactions, see: $(a)$ T. Pu, H. Tian, M. E. Ford, S. Rangarajan and I. E. Wachs, Acs Catal, 2019, 9, 10727-10750; (b) C. Dai, J. Zhang, C. Huang and Z. Lei, Chem. Rev., 2017, 117, 6929-6983; (c) A. E. Wendlandt and S. S. Stahl, Angew. Chem., Int. Ed., 2015, 54, 14638-14658; (d) K. Liu, H. Ou, X. Shi, X. Dong, W. Ma and J. Wei, Chinese J. Org. Chem., 2014, 34, 681-692.

15 For selected reviews on photocatalytic selective oxidation, see: (a) L. Chen, J. Tang, L.-N. Song, P. Chen, J. He, C.-T. Au and S.-F. Yin, Appl. Catal. B-Environ., 2019, 242, 379-388; (b) X. Lang, J. Zhao and X. Chen, Angew. Chem., Int. Ed., 2016, 55, 4697-4700; (c) N. Zhang, Y. Zhang, X. Pan, X. Fu and Y. Xu, Sci. Sin. Chim., 2011, 41, 1097-1111. 